\title{
Decitabine combined regimen in the therapy of Blastic plasmacytoid dendritic cell neoplasm: case report
}

\author{
Jun Guan ${ }^{1}$, Ying Zhou ${ }^{1}$, xia $\mathrm{Mao}^{2}$, Liang Zou ${ }^{1}$, and Hui Cheng ${ }^{1}$ \\ ${ }^{1}$ Wuhan No 1 Hospital \\ ${ }^{2}$ Tongji Hospital of Tongji Medical College of Huazhong University of Science and \\ Technology
}

December 12, 2021

\begin{abstract}
We enrolled a patient diagnosed with blastic plasmacytoid dendritic cell neoplasm (BPDCN). We have found that TET2, KRAS and BRAF may be involved in the development of the disease, and the combination therapy of Decitabine (DAC) and Arsenic acid (ASO) may be effective for BPDCN harboring the TET2 mutations.
\end{abstract}

\section{Hosted file}

20211201BPDCN.doc available at https://authorea.com/users/450729/articles/549023-decitabinecombined-regimen-in-the-therapy-of-blastic-plasmacytoid-dendritic-cell-neoplasm-casereport
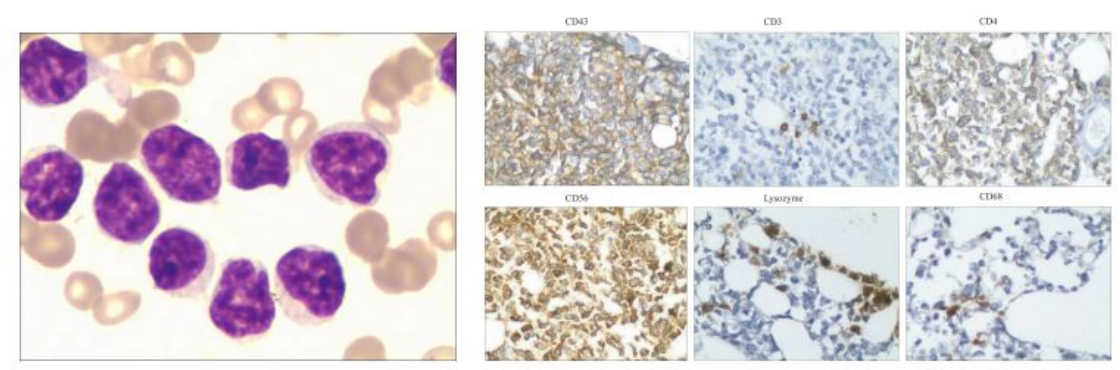


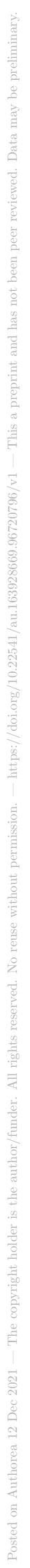
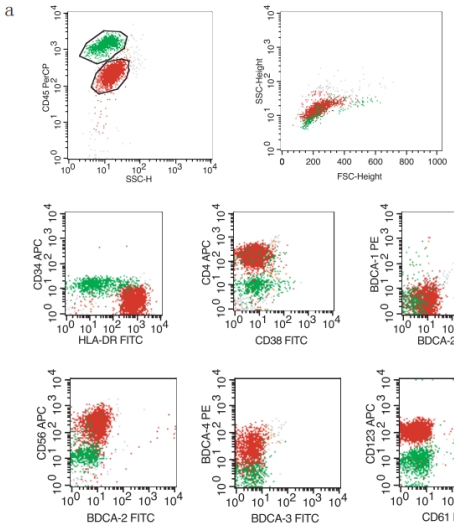
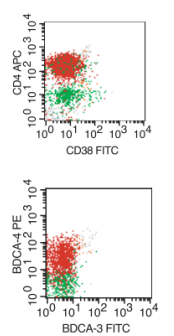
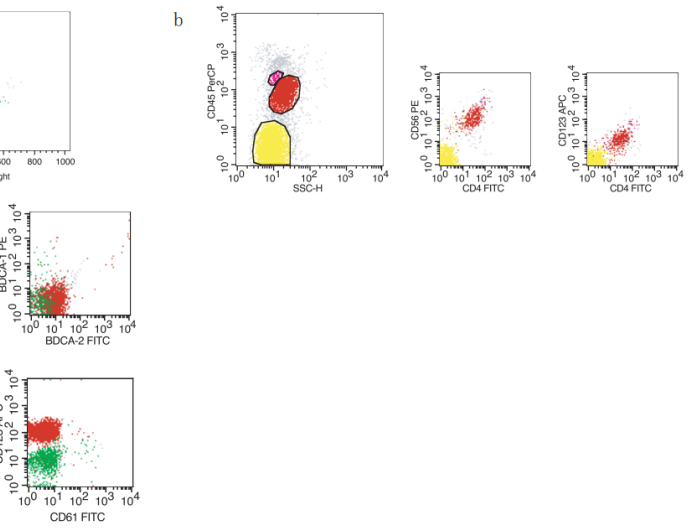

2 